\title{
Gastrointestinal Stromal Tumor pN1 TNM
} Finding v8

National Cancer Institute

\section{Source}

National Cancer Institute. Gastrointestinal Stromal Tumor pN1 TNM Finding v8. NCI

Thesaurus. Code C136766.

Gastrointestinal stromal tumor with regional lymph node metastasis. (from AJCC 8th Ed.) 